\title{
Teacher time outs in rehearsals: in-service teachers learning ambitious mathematics teaching practices
}

\author{
Kjersti Wæge $^{1}$ (D) . Janne Fauskanger ${ }^{1,2}$ (D)
}

Published online: 27 July 2020

(c) The Author(s) 2020

\begin{abstract}
The article focuses on rehearsals as part of a practice-based approach to professional development. Fourteen Norwegian elementary in-service teachers (ISTs) collaborate in learning cycles of enactment and investigation, where the overarching aim is to learn to enact the practices that constitute ambitious mathematics teaching. Rehearsals are an important part of these cycles. We examine the patterns of use of teacher time outs (TTOs) in rehearsals and how TTOs enable the ISTs to learn core practices of ambitious teaching. The findings reveal that approximately $60 \%$ of the time in rehearsals is spent on ISTs' teaching and $40 \%$ on TTOs. The TTOs enable the ISTs to learn together the practices of using representations, aiming towards goals, launching problems, organising the board and facilitating student talk. The findings reveal that the participants were able to work simultaneously on multiple practices, and a recurrent theme in the TTOs is representing students' ideas as accurately as possible whilst simultaneously considering the mathematical correctness of the representations.
\end{abstract}

Keywords Mathematics teaching $\cdot$ Rehearsals $\cdot$ Teacher time out $\cdot$ Professional development $\cdot$ Core practices $\cdot$ Ambitious teaching

\section{Introduction}

Mathematics instruction that aims to develop all students' conceptual understanding, procedural knowledge, adaptive reasoning and engagement in mathematical problem solving is often referred to as ambitious mathematics teaching (e.g. Lampert et al. 2010). Among the principles of ambitious teaching are: treating students as sense-makers; engaging deeply with students' thinking; designing instruction so that all students have equitable access to

Kjersti Wæge

kjersti.wage@ntnu.no

Janne Fauskanger

janne.fauskanger@uis.no

1 Norwegian Centre for Mathematics Education, Norwegian University of Science and Technology, Trondheim, Norway

2 Department of Education and Sports Science, Faculty of Arts and Education, University of Stavanger, Stavanger, Norway 
learning; and seeing teaching as both intellectual work and a craft (e.g. Ghousseini et al. 2015; Kazemi 2017; Lampert et al. 2013). These principles involve knowing the students, developing positive relationships and being responsive to students in culturally appropriate ways (Ghousseini et al. 2015). The aim of professional development (PD) is to support in-service teachers (ISTs) in learning the complex and demanding endeavour of ambitious teaching (e.g. Lampert et al. 2010; McDonald et al. 2013).

Drawing on research findings recommending that PD should aim to build ISTs' mathematical knowledge and their ability to use it in practice, Kazemi and Hubbard (2008) suggest new directions for studying and designing PD. They recommend that the design of and research on PD should include enactments of routine activities, or what Grossman and McDonald (2008) refer to as approximations of practice. This term refers to opportunities "to enact elements of practice with a high degree of support and under conditions of reduced complexity" (Grossman et al. 2018, p. 9). Kazemi and Hubbard (2008) suggest that collective analysis of practice, such as planning a lesson and discussing student work coupled with approximations of practice, can be productive for student learning. As ambitious teaching is grounded on student ideas, it is crucial for ISTs to learn to enact instruction that is thoughtfully responsive to students' in-the-moment thinking. Kavanagh et al. (2020) argue that designing scaffolded practice opportunities for ISTs is important for supporting their learning of adaptive instruction. Moreover, Chapman (2016) argues that we need to understand how PD can engage ISTs in all interconnected aspects of practice. Approximations of practice might be a pedagogy that does just this.

The focus of our study is on the rehearsal, a pedagogy that approximates the work of ambitious teaching by giving ISTs opportunities to work together on trying out and discussing teaching strategies and moves that are responsive to students' contributions (e.g. Kavanagh et al. 2020; Kazemi et al. 2016; Lampert et al. 2013). Rehearsals are embedded within cycles of enactment and investigation, where an IST leads an instructional activity with colleagues acting as students. The teacher educator acts as both supervisor and student and is thus in a position to direct the focus of the instruction on key aspects of ambitious teaching and important mathematical ideas. In the rehearsals, the participants can pause the instruction by initiating a teacher time out (TTO $)^{1}$ so they can think out loud together in the moment, discuss how the teacher might respond to student contributions and determine the direction of the further instruction (Gibbons et al. 2017). After the TTO, instruction continues. Rehearsals allow the ISTs to collectively consider in-the-moment decision-making and then try out the ideas.

Rehearsals of mathematics teaching have been studied in the context of initial teacher education (e.g. Kazemi et al. 2016; Lampert et al. 2013). Some studies in the context of PD show promising results (e.g. Kavanagh et al. 2020), but more research is needed on ISTs' learning in and from rehearsals. The purpose of the present study is to provide new insights into rehearsals in PD. The following two research questions are addressed: (a) What are the patterns of use of TTOs within rehearsals? (b) In what ways do TTOs in rehearsals enable learning situations for ISTs to collectively consider the practices of ambitious teaching? This article draws on data from the Mastering Ambitious Mathematics teaching (MAM) project, where ISTs collaborate in cycles of enactment and investigation with the overarching aim of learning to enact the practices that constitute ambitious teaching and developing identities as teachers who care about student thinking. Rehearsals are an important part

\footnotetext{
1 Researchers use different terms, for example TTOs, pauses, and Teacher Educator/Novice Teacher exchanges, to refer to very similar phenomena.
} 
of these cycles. We answer the research questions by analysing video recordings of 18 rehearsals.

\section{Perspective on learning}

Our work is informed by sociocultural views on teacher learning, and central to this perspective is understanding learning as it emerges through participation in activity. We draw on Lave's (1991) description of learning, thinking and knowing as "relations among people engaged in activity in, with, and arising from the socially and culturally structured world" (p. 67). From this perspective, teacher learning is not just about acquiring new knowledge but also about developing the ability to engage in particular practices and developing identities. According to Wenger (1998), practice is characterised by three dimensions. The first is mutual engagement. "It [practice] exists because people are engaged in actions whose meanings they negotiate with one another" (p. 73). The second is the negotiation of a joint enterprise. The participants' collective process of negotiation results in an enterprise that reflects their mutual engagement. The third dimension of practice is a shared repertoire. Participants develop resources for negotiating meaning, for example routines, words or concepts, in their joint pursuit of the enterprise. Wenger (1998) argues that educational designs should provide opportunities for engagement, exploration and reflection, where we can find innovative ways of engaging the participants in meaningful processes, actions and discussions. In the present study, we examine how rehearsals provide learning situations for ISTs to collectively consider the principles and practices of ambitious teaching, that is, we study how rehearsals provide opportunities for active engagement in mutual processes of negotiation of meaning.

To engage ISTs in learning ambitious teaching and identifying themselves as teachers who care about student thinking, the teacher educators in our study developed a community where the ISTs were positioned as responsible and contributing members (Greeno 2007). Moreover, the teacher educators created situations to develop the ISTs' competence and give them a sense of authority and accountability (Lampert et al. 2015). The teacher educators conveyed the view that competent learners ask questions when something is unclear and when they are not sure what to do in a teaching situation. These questions might further the collective effort to understand and learn ambitious teaching. To establish a community where the ISTs have authority and accountability for the knowledge and understanding they construct, the teacher educator encouraged them to explain and justify their instructional ideas, to find multiple strategies and try to understand what other ISTs say and do. Thus, the teacher educators aimed to develop a setting where ISTs could be engaged together in the joint enterprise of learning ambitious teaching in which questions and disagreements were viewed as a productive part of the enterprise. As discussed below, the design of rehearsals intentionally follows our view on learning because it allows the ISTs to share their decision-making.

\section{Effective forms of professional development}

A growing body of research on effective forms of PD grounded in sociocultural views of learning provides suggestions for PD: it should be sustained over time, build systemic support and offer ISTs opportunities for active learning (e.g. Desimone 2009; 
Garet et al. 2001; Putnam and Borko 2000). Furthermore, PD should be connected to and contextualized in practice and enable ISTs to develop their knowledge and ability to use new ideas in practice (e.g. Ball and Bass 2003; Ball and Even 2009; Kennedy 2016). Research suggests that PD can help ISTs learn to notice and analyse students' mathematical thinking and understanding (e.g. Jacobs et al. 2007; van Es and Sherin 2008), which is a key principle of ambitious teaching. While it is well documented that in-themoment instructional decisions are highly complex (Richards and Robertson 2015), few existing PD models are designed to support teachers' engagement with these considerations or to support ISTs' integration of new ideas and methods into their own practice (Kennedy 2016). The current study aims to address this gap in the research literature.

An extensive body of research indicates that collective participation is an important feature of PD programs (e.g. Desimone 2009; Vangrieken et al. 2017). Based on a review of the effectiveness of PD programmes, however, Kennedy (2016) argues that "we need to move past the concept of learning communities per se and begin examining the content such groups discuss and the nature of the intellectual work they are engaged in" (p. 972). Moreover, based on a synthesis of research related to the professional learning of mathematics teachers, Goldsmith et al. (2014) claim that research often focuses on the effectiveness of PD programmes rather than on ISTs' learning and argue that we need research that provides a systematic description of the PD approach and explores the ways IST learning opportunities are enacted. Exploring rehearsals is one way to meet this need.

\section{Research on rehearsals}

The Learning in, from and for Practice project (LTP) (e.g. Ghousseini 2017; Kazemi et al. 2016; Lampert et al. 2013) worked extensively on designing and studying rehearsals with novice mathematics teachers. The findings revealed that rehearsals allowed novice teachers to share their decision-making with each other and provided opportunities to learn adaptive teaching while developing knowledge, skills and identities. They also found that the nature of rehearsals is affected by novice teachers' experience of teaching children. Ghousseini et al. (2015) showed how a question sequence was used in rehearsals to support novice teachers in learning to elicit and respond to students' thinking in an adaptive manner that adhered to the principles of ambitious teaching.

Whereas most research on rehearsals has focused on initial teacher education, more recent research has studied rehearsals in PD. Kavanagh et al. (2020) found that by reducing ISTs' choices in rehearsals "it was possible to focus more tightly on how best to give full attention to, understand, and respond to student ideas" (p. 11). In a previous study within the MAM project, Fauskanger and Bjuland (2019) investigated how one cycle of enactment and investigation offered opportunities for ISTs to learn ambitious teaching of multiplicative properties. They found that the ISTs had opportunities to learn mathematical language, strategies and multiple key ambitious practices. In a pilot study of the MAM project, Valenta and Wæge (2017) investigated what characterised TTOs in rehearsals and found that TTOs mainly involved discussions on using representations, aiming towards mathematical goals, addressing student thinking and eliciting and responding to students' ideas. Although the research body on rehearsals is growing, very little is known about them in the context of PD. The current study aims to shed more light on this matter. 


\section{Setting and participants}

\section{Selection of participants}

Thirty ISTs from ten public Norwegian elementary schools participated in the MAM project. All elementary schools in one urban municipality were invited to apply for the project. Ten schools applied, and all were approved by the education authority in the municipality. At each school, the principals selected three ISTs (teaching all subjects) who wanted to learn ambitious mathematics teaching and whom they thought could subsequently serve as mentors for their colleagues so this practice could be expanded to the whole school. The principals were invited to attend the sessions and frequently did so. The 30 ISTs were divided into four groups. One group consisted of ISTs that did not want to be part of the research study. We picked two out of the three remaining groups at random; thus, the ISTs in our study are 14 elementary school ISTs (years 1-7). Their teaching experience varied: five ISTs had 1-5 years of experience, three had 6-10 years of experience, and six had more than 10 years of experience. Prior to the course, some of the ISTs used certain elements of ambitious teaching in their own practice; however, none of the ISTs had extensive experience in practising ambitious teaching.

\section{Setting}

The aim of the MAM project was for the ISTs to learn core practices and principles of ambitious teaching that guide the ISTs' enactment of these practices and also to learn to enact the practices in an adaptive manner. Core practices are "identifiable components (fundamental to teaching and grounded in disciplinary goals) that teachers enact to support learning" and consist of "strategies, routines, and moves that can be unpacked and learned by teachers" (Grossman et al. 2018, p. 4). The practices we worked on include launching problems, using mathematical representations, aiming towards a mathematical goal, facilitating student talk and eliciting and responding to students' mathematical ideas (Lampert et al. 2013).

The MAM project consisted of 12 sessions over a period of 2 years where the sessions were held at one of the participating schools. In designing the MAM project, we took our lead from the LTP project (Lampert et al. 2013). To help the ISTs learn the practices identified as key to the principles of ambitious teaching, we gave them repeated opportunities to rehearse a set of intentionally selected instructional activities embedded in a cycle of enactment and investigation (see Fig. 1). The project began with a session where the ISTs were introduced to the principles and practices that guided the substance of the project and the instructional activities they would be learning. In nine of the sessions, a full cycle of enactment and investigation was carried out and each of these sessions focused on one of the following instructional activities: choral counting, quick images, strings, problem solving and games (for descriptions of the instructional activities, see Kazemi and Wæge 2015). These activities are designed to allow inquiry into the relationships between practices, principles and the mathematical content we wanted the ISTs to learn and enact in interaction with students (e.g. Lampert et al. 2010). The instructional activities reduce the complexity of the ISTs' learning by supporting them in eliciting student thinking and in making judgments on how to respond in principled, instructive ways (Lampert et al. 2013). In the two remaining sessions, the participants worked on the challenges of ambitious teaching and on plans 


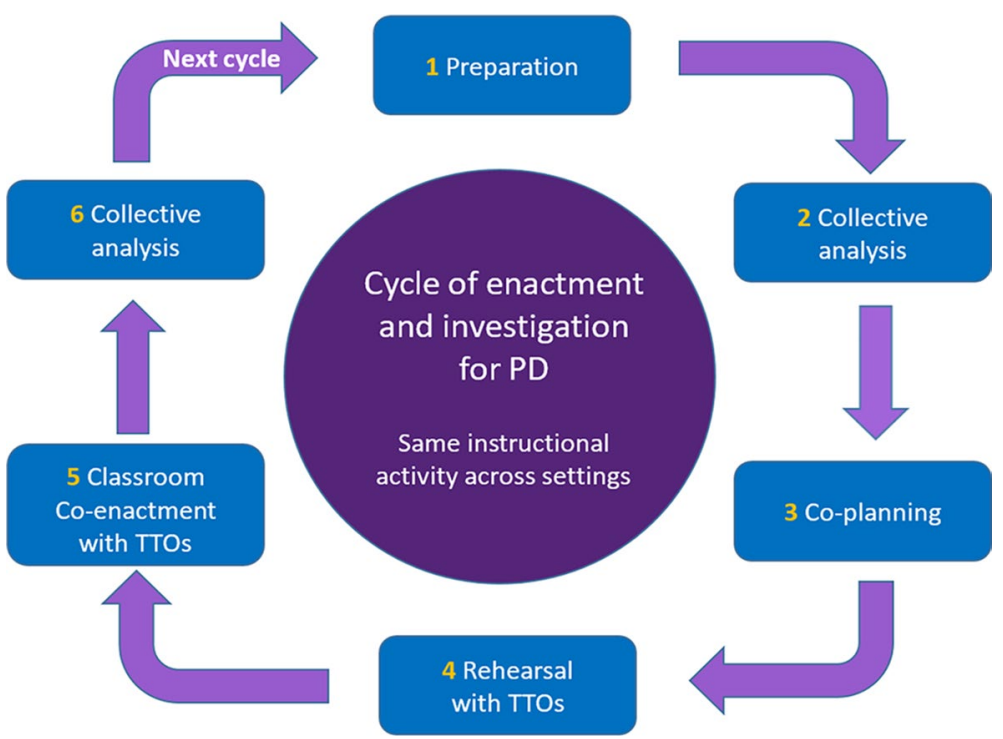

Fig. 1 Cycle of enactment and investigation for professional development (adapted to PD from Lampert et al. 2013, p. 229)

for implementation in their own schools. The mathematical content of the project focused on number sense.

\section{Cycles of enactment and investigation for professional development}

In sessions with a full cycle of enactment and investigation, the ISTs were divided into four groups of seven to eight participants, guided by a teacher educator. The group structure enabled them to work together in planning, rehearsing, enacting and debriefing instruction. Each cycle, focusing on one instructional activity, was structured in the following way:

1. Preparation Before the session, the ISTs read an article on various themes (e.g. the relation between instructional activities and important mathematical ideas, talk moves, student strategies and problem solving) and watched a video recording of a particular instructional activity enacted in a classroom context. They also read a description of the activity they would work on in the session. Moreover, some of the ISTs had—on their own initiative - tried out the instructional activity with students in their own classroom.

2. Collective analysis The session started with the whole group of ISTs collectively analysing the article and video, guided by the teacher educators. They analysed principles and practices central to the instructional activity they had observed in the video and subsequently discussed how the teacher used these in a responsive manner in orienting the students towards the goals for the lesson.

3. Co-planning Groups of ISTs and teacher educators co-planned to teach the instructional activity to a group of students using the principles and practices they had analysed and discussed in the collective analysis. 
4. Rehearsal A selected IST (or a pair of ISTs) rehearsed the group's plan for enacting the activity, while the other ISTs and teacher educators acted as students. During the rehearsal, all members of the group could initiate TTOs.

5. Classroom co-enactment The ISTs co-enacted the activity with a group of students (aged 11-12). The selected IST led the activity, but all members of the group were responsible for the instruction and could take TTOs.

6. Collective analysis The ISTs and teacher educators met in their groups to analyse the co-enactment and reflect on their own learning, focusing on how the principles and practices central to the instructional activity played out with the students. This was followed by a collective analysis and reflection in the whole group, and preparation for the next cycle.

The focus of our study is on TTOs in rehearsals. It should be noted that the learning situations enabled by TTOs in rehearsals are dependent on and shaped by the conversations in the other phases of the learning cycle.

\section{How rehearsals were organised}

The teacher educators encouraged the ISTs to assume the role as the teacher, which they always did. One (or two) of the ISTs volunteered to lead the rehearsal while the other ISTs and teacher educators played the part of students. The members of the group could pause the instruction by taking a TTO to raise a topic of their choice. At the end of the project, all ISTs had led the rehearsal of one instructional activity or more. Each rehearsal was allocated a maximum of $30 \mathrm{~min}$, but was often shorter.

\section{Design of PD}

The MAM project has been modelled on research on effective forms of PD. It provides opportunities for ISTs to engage in instructional activities to learn more about students' mathematical thinking and to collectively plan for, rehearse, co-enact and reflect on ambitious teaching. The design allows for active involvement in mutual processes of negotiation of meaning to create a joint enterprise (Wenger 1998). The ISTs work with a new set of experiences, and the nature of the activities shape and are shaped by how they participate. By drawing on the instructional activities as a common tool, they engage in collective exploration, observation and reflection. The teacher educator guides these collaborative efforts, thus offering the ISTs a community of practice within which they can learn the norms of ambitious teaching and develop a shared conceptual framework, or a shared repertoire (Wenger 1998) that can enable adaptive instruction (Lampert et al. 2013).

It is thus important to look at tools, such as instructional activities, and the social settings in the learning cycle to study what kinds of learning situations arise. 


\section{Method}

\section{Data collection and analysis}

We draw on a subset of our data involving all rehearsals from the MAM project. We analysed nine rehearsals from each of the two teaching groups for a total of 18 rehearsals. The unit of analysis is TTOs in rehearsals. We identified a TTO as the point in time when enactment was explicitly paused so that the ISTs and teacher educators could ask questions, think out loud together and consider their instructional decisions before continuing with the instruction (Gibbons et al. 2017).

Studio-code video-analysis software was used to code the TTOs, both within and across the video-recorded rehearsals. We created timelines for each rehearsal to pinpoint the TTOs and to code what was being worked on within each of them. By coding the video directly, both verbal and visual cues could be considered.

We started the analysis by coding for eight a priori codes: launching problems; using representations; aiming towards a goal; facilitating student talk; eliciting and responding; mathematics; student error; and student thinking (Lampert et al. 2013). They represent codes used in other studies on rehearsals that we saw examples of in rehearsals in a pilot study for the MAM project (Valenta and Wæge 2017). Additional codes emerged from the data that revealed important aspects of the TTOs (see Table 1). In many of the TTOs, we used multiple codes to pinpoint the aspects of practice being worked on. Table 1 shows a list of the relevant a priori codes and emergent ones on which we based our analysis. For example, the TTO in which the teacher asked "Do I need to write it in another way then, or? [after having represented what a student said in the number line]", and the teacher educator responded by suggesting "You can also write using symbols like you have done there [points at the board]" would have been coded with "use of representation".

Both authors independently coded each segment that had been identified as a TTO. Disagreements were resolved through review of the data and discussions. After the coding was completed, we made several analytical reviews of the data, compiling data segments according to their codes and reviewing the entire corpus qualitatively. We made matrices that enabled us to look for commonalities across the TTOs and wrote analytical memos to help us connect the data (Corbin and Strauss 2008). We selected representative examples from the data material, chosen because they were both representative of their category and could be presented without long elaborations on the preceding and succeeding contexts, to present our findings.

\section{Findings}

\section{Patterns of TTO use within rehearsals}

The analysed rehearsals were of varying length, taught by a number of ISTs and focused on varying instructional activities. The rehearsals lasted on average 16 min, with an average of ten TTOs per rehearsal. A total of 175 TTOs were analysed across all 18 rehearsals. Approximately, $60 \%$ of the time was spent on ISTs teaching and $40 \%$ on TTOs. Thus, the rehearsals offered opportunities to both enact the lesson plan and to raise questions, receive feedback and discuss practice. An average of ten TTOs per 


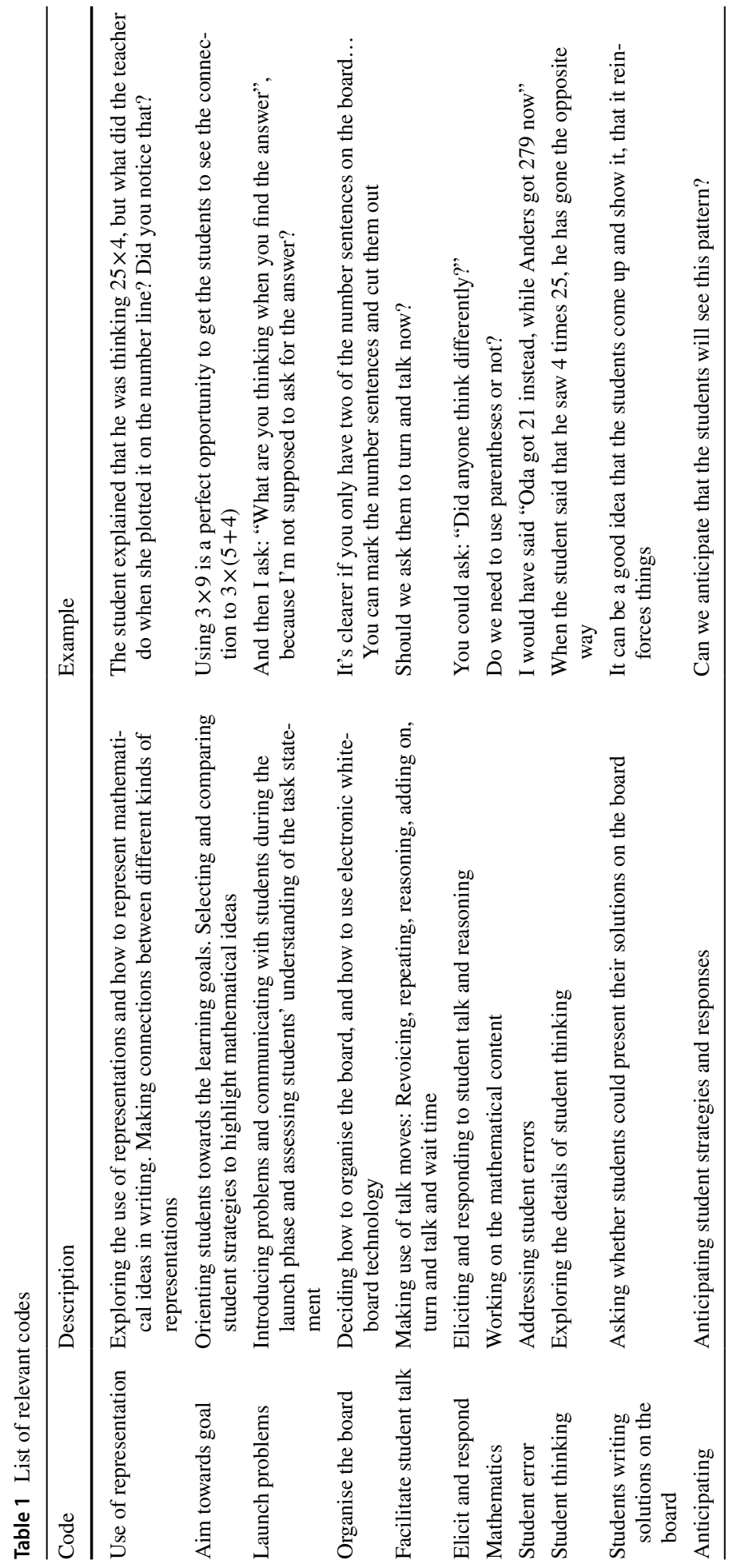


Table 2 Frequency of the five key practices, per TTO and per rehearsal

\begin{tabular}{lll}
\hline Teaching practice & $\begin{array}{l}\% \text { of all TTOs } \\
(n=175)\end{array}$ & $\begin{array}{l}\% \text { of all rehearsals } \\
(n=18)\end{array}$ \\
\hline Use of representations & 29 & 78 \\
Aiming towards goals & 25 & 89 \\
Launching a problem & 23 & 89 \\
Organising the board & 18 & 67 \\
Facilitating student talk & 16 & 68 \\
\hline
\end{tabular}

rehearsal shows the back-and-forth pattern that occurred. The TTOs lasted $61 \mathrm{~s}$ on average, but some were as long as 8 mins and some as short as 1-2 s. However, these extremes were rare. Approximately, $46 \%$ of the TTOs were initiated by the teacher, $30 \%$ by another IST and $24 \%$ by the teacher educator. Thus, most interactions $(76 \%)$ were initiated by an IST. This gives us some insight into how the TTOs facilitate ISTs' active engagement in the collective work of learning.

\section{What was addressed in the TTOs?}

Our analyses show that the following practices of ambitious teaching were the most salient during the TTOs: use of representations; aiming towards goals; launching problems; facilitating student talk; and organising the board (Table 2). The practice of organising the board, as it emerged from the data, is related to the use of representation and has not been emphasised in the previous research on rehearsals. We will explain below how our participants became interested in discussing this issue.

Below, we describe how the teacher educator and ISTs worked on these practices in rehearsals. For each practice, we describe how rehearsals enabled the ISTs to collectively learn the ambitious practices and principles and decision-making that is responsive to students' ideas. Although we discuss the practices separately, we note that many of the TTOs involved simultaneous work on multiple aspects of practice, and some of the examples we have chosen illustrate this.

Table 2 provides an overview of the frequency of occurrence of each of the five practices. This information is organised in two ways, according to: (a) the percentage of all TTOs that included this practice and (b) the percentage of all rehearsals that included this practice.

The percentage of all TTOs that included a particular category shows how often this category was worked on across all TTOs, whereas the percentage of all rehearsals shows how frequently a category occurred across all 18 rehearsals. Table 2 shows that the TTOs focused predominantly on the categories use of representation (29\% of all TTOs) and aiming towards goals (25\% of all TTOs). These two categories also frequently occurred across rehearsals (78\% and $89 \%$, respectively). The category launching a problem was among the most frequent across rehearsals (89\% of all rehearsals), and the participants worked on this category in $23 \%$ of all TTOs. The categories organising the board (18\% of all TTOs) and facilitating student talk $(16 \%$ of all TTOs) occurred less frequently overall, but still occurred in more than $65 \%$ of all the rehearsals. 
Fig. 2 Teacher represents student ideas by using an open number line

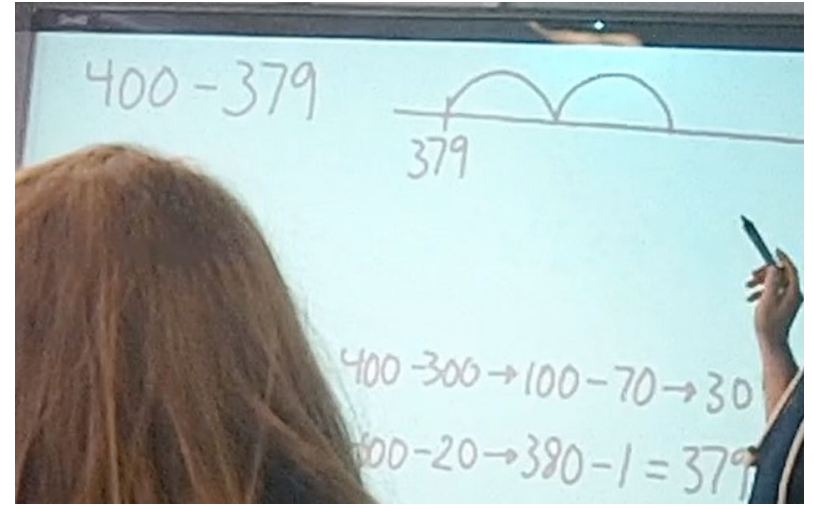

\section{Use of representations}

Representing students' mathematical ideas in writing and making connections between student talk and representations and between different kinds of representations-such as the open number line, arrays and tables-were key aspects in most rehearsals and many TTOs (29\%). We present two representative examples to show what aspects of representations the collective sensemaking in TTOs focused on. For example, recording the students' ways of thinking as accurately as possible was emphasised. This is illustrated in the example below from a rehearsal of a string, starting with the task 400-379 (see Fig. 2).

We join the rehearsal as the teacher represents a student ${ }^{2}$ strategy on the open number line. He pauses and asks:

1 Teacher So I write [that the student jumps by 10] in between [he draws over the arcs on the number line]?

$2 \mathrm{TE}^{\mathrm{a}} \quad$ [Writes] plus 10

3 IST1 On the arc

4 Teacher I don't write what they get down here [points to the number line]?

5 IST1 No [teacher writes plus 10 over each arc]

6 TE If Kari [the student] had said it

7 Teacher Yeah, because here you [the student] said plus 1 is 380 [points to another calculation on the board], so then I would have written down next [illustrates that he wants to draw a little arc and write the number on the number line]. For what she had, right? She has 379 plus 1 [draws an arc and writes 380 on the board]. Then she [the student] said that she got 380

8 TE Yes, then you can write it down [380 on the number line]. (Session 5, March 23, 2017, strings, group 3)

${ }^{\mathrm{a}}$ Teacher educator

The teacher asked for help in representing the student's thinking on the open number line (lines 1, 4, 7). The other participants tried to scaffold his representations of the student's ideas (lines 2, 3, 5), focusing on capturing what the student had said and representing the student's strategy as accurately as possible (lines 5, 6, 8).

${ }^{2}$ When we refer to "student" in the rehearsals, we mean the "IST acting as student". 
The participants also discussed how to write the number sentences to represent student thinking whilst simultaneously considering the mathematical correctness of the number sentences. For example, they discussed (1) if and how the teacher might include parentheses when representing students' thinking to preserve the mathematical correctness of the number sentences (see example, next section); (2) if the teacher should use arrows instead of the equal sign to avoid misuse of the equal sign (see example below); and (3) the degree to which the teacher should focus on the convention relating to the order of factors when connecting different kinds of representations, such as quick images and number sentences.

Below is an example from a rehearsal of a game. The teacher represented one student strategy on the board. He wrote: $9-5=4 \times 3=12: 6=2 \times 4=8$. We join the rehearsal as one of the observing ISTs intervenes:

\begin{tabular}{lll}
\hline 1 & IST1 & Then the question is/ \\
2 & IST2 & Then the question about notation is relevant \\
TE & $\begin{array}{l}\text { Yes, and it can't be [written] like that [points to the } \\
\text { number sentence on the board]... [the discus- } \\
\text { sion continues]. (Session 9, November 16, 2017, } \\
\text { games, group 3) }\end{array}$ \\
\hline
\end{tabular}

The use of equal signs in the number sentence was not mathematically correct, and IST2 suggested they might take a closer look at notation use (line 2). The teacher educator supported this suggestion, pointing out that they needed to find another way to write the different steps in the student's strategy (line 3). This led to a discussion on how to represent the different steps in a way that did not display an incorrect use of the equal sign. The ISTs were not accustomed to using an arrow instead of the equal sign when recording student thinking. The teacher educator introduced the use of arrows to the ISTs and in the example above, the participants concluded that they would replace the equal sign with arrows to avoid misusing the equal sign $(9-5 \rightarrow 4 \times 3 \rightarrow 12: 6 \rightarrow 2 \times 4=8)$.

The examples above illustrate how the TTOs enabled learning situations for ISTs in which the participants were making sense together of the practice of representing students' thinking. They were negotiating how to represent student ideas as accurately as possible whilst simultaneously paying attention to the mathematical correctness of the representation. Thus, the ISTs were trying to make sense of several practices simultaneously and also to see them in relation to each other. Furthermore, the analysis shows that they were trying to figure out how to connect different kinds of representations. Our analyses also show how TTOs provided learning situations for the ISTs' collective considerations on how to connect the enactment of the practices to principles of ambitious teaching. We see in the first example how the participants draw on two principles, treating students as sense-makers and engaging deeply with students' thinking, when considering how to represent students' ideas.

\section{Aiming towards a goal}

A fourth of the TTOs addressed the practice of drawing the students' attention to the mathematical learning goal for the lesson. The participants discussed which student strategies the teacher might choose to present on the board and which of the presented strategies could be chosen to elaborate on specific mathematical concepts and ideas. Note that this 
Fig. 3 Student strategies for finding the number of dots in a quick image

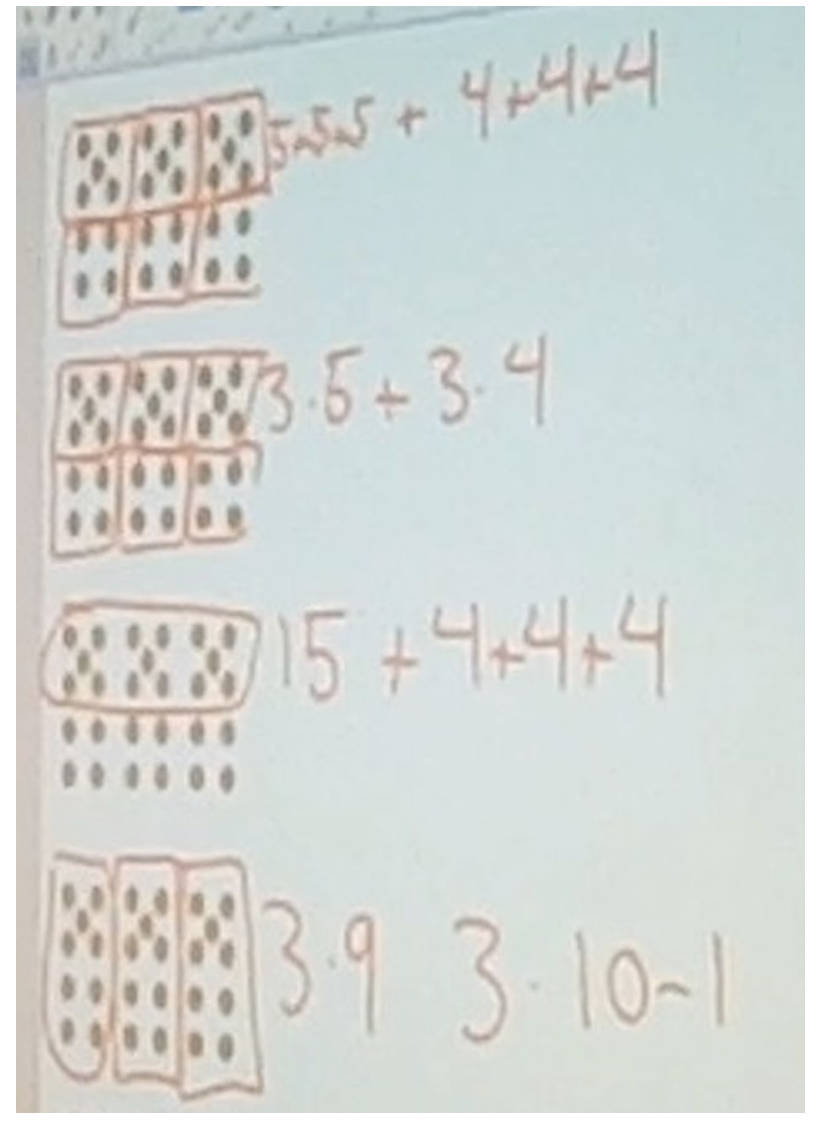

category includes discussions on formulating questions and eliciting students' strategies to focus on the goal for the lesson.

They also discussed how the teacher might use visual representations to facilitate the students' understanding and help them to explore patterns and see connections between different strategies. The example below from a rehearsal of a quick image illustrates these considerations. The learning goal for the lesson was to learn the distributive property of multiplication $(a \times(b+c)=a \times b+a \times c)$. The students were shown a quick image for $a$ few seconds. They were then asked to say how many dots they saw and explain how they found the answer. Just prior to the TTO, the teacher represented several student strategies on the board, both by using the quick image and by writing number sentences (see Fig. 3). Note the two strategies written on the board ${ }^{3}: 3 \times 5+3 \times 4$ and $3 \times 9$. We join the rehearsal as the teacher represented the student strategy "three times ten minus one" on the board: $3 \times 10-1$. The teacher educator intervened:

1 TE But then the idea of using parentheses is interesting [refers to the number sentence $3 \times 10-1$ on the board]

3 In Norway, "•" is used as a multiplication sign. 
Fig. 4 Student strategies represented on the board

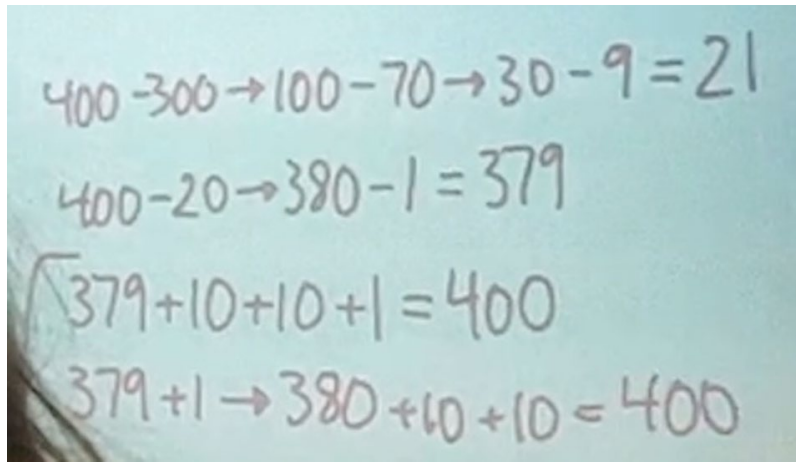

2 IST1 I was just thinking the same thing. I was thinking that this [the number sentence] with $3 \times 9$ [on the board] is an excellent opportunity to get them [the students] to see $3 \times(5+4)$. You [teacher] can ask them "Does anyone see 9 in another way?" Then we add 5 and 4 , and then you [teacher] write down $3 \times(5+4)$

3 Teacher Yeah, and if it's suggested [points to $3 \times 10-1$ ], then I can ask if they can think of 9 in another way, also... [the discussion continues]. (Session 3, November 24, 2016, quick image, group 2)

A few minutes after the teacher represented the strategy $3 \times 9$ on the board, one of the ISTs marked this representation as something to address, suggesting follow-up questions so they could focus on the distributive property. He suggested they could use $3 \times 9$ as a starting point to show that $3 \times(5+4)=3 \times 5+3 \times 4$ (line 2 ). This suggestion led to a discussion on how the teacher could use the students' strategies to make them more aware of the distributive property (line 3). The example reveals how one of the participants saw an opportunity to use the students' strategies to point out important mathematical ideas. After this, in the same TTO, the participants took a closer look at the number sentence $3 \times 10-1$ (on the board) and discussed how the teacher could proceed and write a parenthesis $(3 \times(10-1))$ so that the number sentence was a mathematically correct representation of the student's idea. This is another example of using representations.

The participants also discussed what questions the teacher could ask to direct the students towards the lesson goal. Below is an example from a previously described rehearsal of a string, starting with 400-379. The goal for the lesson was to learn the strategy of adding up, that is, starting with the smallest number (379) and adding up to the biggest number (400) to find the difference between the two numbers. Just prior to the TTO, the teacher represented several strategies on the board (see Fig. 4).

In the first two, the students used the strategy of subtracting and in the last two, the strategy of adding up, which was what the teacher wanted to focus on. We join the rehearsal as the teacher tells the students that they are going to take a closer look at two of the student strategies:

1 Teacher I would like to point out that everyone has had correct thinking, and you [the students] have presented good ideas. I would like us to take a closer look here [points to the two lower number sentences on the board] 
2 IST1 What if you ask: "What's the difference between the two top ones and the two at the bottom [number sentences on the board]?" And then take a closer look at that. And then say that: "Today we'll be looking at how we start with the lowest number and add to it", and ask: "How can we visualise the two lowest ones [the number sentences on the board] on a number line? Then we start with the top one of the two. How would you have shown this on a number line?" And then you [the teacher] draw a number line ... [the discussion continues]. (Session 5, March 23, 2017, strings, group 3)

IST1 interjected to provide an example of how the teacher might inform the students about one another's strategies and about important mathematical ideas by raising a question about the difference between the two groups of strategies. Instead of jumping straight to the adding-up strategy, IST1 suggested that the students should think about the difference between the two first and the two last strategies. Thus, she offered a suggestion that could help the students to understand the difference between subtracting and adding up (line 2). IST1 also provided examples of follow-up questions to ask the students to orient them towards the adding up strategy and to facilitate their understanding by using the open number line (line 2). Her suggestion initiated a discussion on how the teacher could invite productive student thinking.

The examples above illustrate how TTOs enabled learning situations for the ISTs in which the participants were negotiating how to use student thinking to promote key mathematical ideas and to reach the learning goal. More specifically, the ISTs were considering which questions to ask, how to formulate follow-up questions, which strategies to select and how to connect different student strategies so they could focus on key mathematical ideas. Because the ISTs had planned the lesson together and were working on learning ambitious principles and practices, the opportunity to pause during instruction gave them a chance to think through teacher actions in relation to the principles of ambitious teaching. In the second example, the IST's suggestion (line 2) and the following discussion reflect the serious attention paid to the principles of treating students as sense-makers and how a teacher might invite productive student thinking. The first example also illustrates how the ISTs draw on this principle by using the students' contributions to connect to the goal of the lesson and asking questions that allow the students to do the thinking (lines 2 and 3). Thus, our analyses show how the participants in TTOs collectively considered how to use the practices and principles adaptively in relationships. The examples also illustrate how the ISTs were active members of the community and initiated discussions and negotiated meanings of the practices and principles of ambitious teaching.

\section{Launching problems}

In all but two of the analysed rehearsals, some of the TTOs were related to the practice of launching problems. The teacher often asked for feedback on the way the problem was posed. This is illustrated in the example below from a rehearsal of a choral count, counting by $4 \mathrm{~s}$, starting at 5 . When posing the problem, the teacher asked the students to try to argue why the patterns occurred. We join the rehearsal as the teacher pauses and asks:

1 Teacher Did I put that well?

2 Other Yes [teacher educator and other ISTs nod and also give confirming answers]. (Session 2, October 20, 2016, choral counting, group 3) 
Fig. 5 Student strategy represented on the open number line

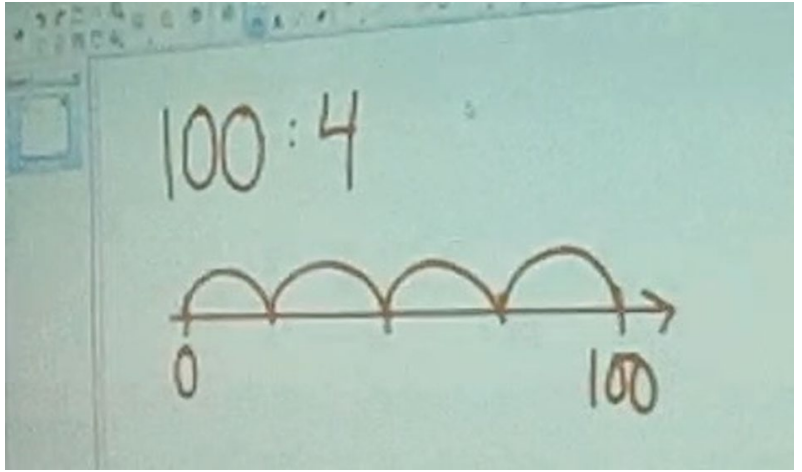

The teacher wanted feedback on the way he posed the problem (line 1). The others nodded in agreement (line 2). In some TTOs, the teacher educator or the ISTs offered specific suggestions on how the teacher could make the problem more comprehensible.

In many of the TTOs where the focus was on launching the problem, the participants discussed how the teacher could draw students' attention to arguing and explaining their thinking. Below is an example of a TTO showing how one of the ISTs raised the participants' awareness of student explanations. We join the rehearsal in group 3 just after the teacher has posed the problem:

1 IST1 I was wondering about something. Justification. Should we say something about that?

2 Teacher Yes?

3 IST2 Why the solution turned out the way it did?

4 IST1 Why? That's where I'm really unsure. In relation to the goal [of the activity], it's obvious that they [the students] should give reasons/

5 IST3 Can't you look at it in relation to, you know: "At 11 o' clock we'll meet back here and see how you have arrived at your solution. Give some thought to how you can explain how you have solved the task"... [the discussion continues]. (Session 8, October 19, 2017, problem solving, group 3)

IST1 asked if the teacher should say something about justification while she presented the task (line 1) and followed up the question by explaining that she was not sure how the teacher might do that (line 4). This question initiated a discussion on how the teacher could orient the students towards reasoning and arguing during the launching phase (line 5).

The analyses suggest that the TTOs enabled learning situations for the ISTs in which the participants were making sense together of the practice of launching problems, drawing on ambitious principles. More specifically, the ISTs were negotiating how they could make the task comprehensible to students and give them a starting point for investigation, drawing on the principle of providing equitable access to learning for all students. Moreover, the ISTs collectively considered how to orient the students' attention towards reasoning and sharing strategies during the launching phase, drawing on the principle of treating students as sense-makers. The TTOs highlighted the ISTs' questions about the practice so they could consider what decisions to make and why. 


\section{Organising the board}

Some of the TTOs (18\%) were related to the organisation of the electronic whiteboard and how space on the board was utilised: where they might write tasks, students' strategies and representations on the board, and how they might place these in relation to each other. How to utilise the whiteboard's functions was an important part of the discussions. To illustrate this, we give an example from a rehearsal of a string, starting with the task $100: 4$ (see Fig. 5).

We join the rehearsal as the teacher represents a strategy on the open number line. The teacher educator initiates a TTO, and we start where she comments on the organisation of the board:

1 TE There's something else I'm thinking about, and that's the placement of the number line and the tasks

2 Teacher Yes, but I was thinking about the length just now seeing as I will soon have $200 \mathrm{~m}$

3 IST1 Yeah, she's going to have $200 \mathrm{~m}$ afterwards

4 IST2 But then you write the sentences under each other. You have to write $200: 8$ under there

5 IST3 Yeah

6 Teacher $\mathrm{Mm}$

7 IST2 Is that what we do? You can move the number line further down. Right at the bottom

8 Teacher No [she tries to move the number line, but does not succeed]

9 IST2 If you mark it first before you move it. You can use the arrow. [Teacher still does not manage to do it. IST2 comes to the board and shows how she can move the number line further down the board]. (Session 6, May 4, 2017, strings, group 2)

In this exchange, the teacher educator drew the ISTs' attention to the written tasks and the number line and how they might place them in relation to each other on the board (line 1). This led to a discussion on various aspects to be considered when deciding where to place them (lines 2-4). IST2 made a suggestion that took these aspects into consideration (line 7). Then, the teacher tried to move the number line using the whiteboard functions, but had problems. IST2 demonstrated how this could be done (lines 8-9).

Another subject in the TTOs was how to organise the whiteboard to point students in the direction of particular student strategies and make connections between different strategies. Below is an example from a rehearsal using a quick image where different student strategies were written on the board (see Fig. 6).

We start when the teacher tells the students that they are going to take a closer look at two of the strategies (she points to two strategies on the board). She hesitates, then stops and asks:

\begin{tabular}{lll}
\hline 1 & $\begin{array}{l}\text { Teacher } \\
\text { IST1 }\end{array}$ & $\begin{array}{l}\text { Should I write on the same [slide] here now? } \\
\text { It would be easier to see if you took the two [strate- } \\
\text { gies] on a new one [points to the two strategies } \\
\text { they want to continue with, } 5 \times 3+4 \times 3 \text { and } \\
(5+4) \times 3 \text { ] }\end{array}$ \\
3 & Teacher & $\begin{array}{l}\text { Got these two/ } \\
\text { Got just these two [strategies], and not the other two } \\
5\end{array}$ \\
IST1 & Teacher & Yeah \\
6 & TE & You can just mark them and cut them out \\
\hline
\end{tabular}


Fig. 6 Student strategies on a quick image represented on the board

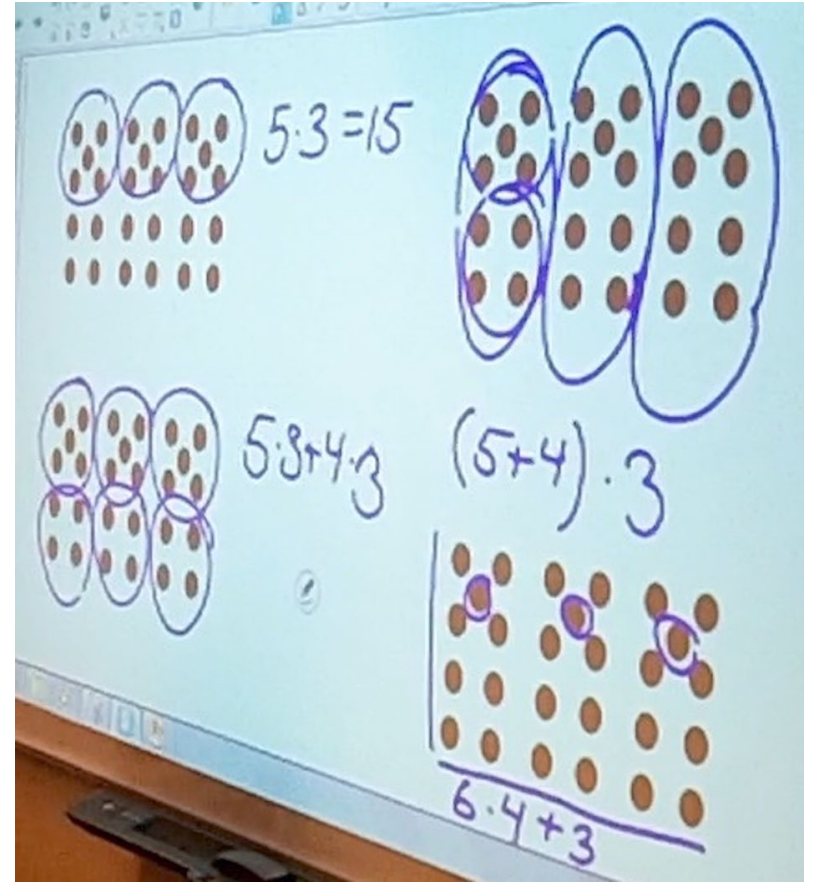

The teacher asked for help in organising the board (line 1). IST1 suggested she might move the two strategies she wanted to focus on to a new slide (lines 2 and 4). The teacher educator supported this, suggesting how to utilise the whiteboard's functions (line 6). IST2 suggested deleting some of the strategies on the board (line 7), and the discussion continued.

As the examples illustrate, the TTOs enabled learning situations for the ISTs in which they considered together how to organise the board to direct the students' attention to particular strategies and thus support them in making connections between various strategies drawing on principles of ambitious teaching. The participants were trying to figure out how the teacher might place tasks, student strategies and representations in relation to each other. Many Norwegian classrooms have electronic whiteboards, and the TTOs enabled learning situations on making sense together of the whiteboard's functions, the when and why to make use of the numerous options the whiteboard offers, such as copying selected strategies to a new slide or moving them to another place on the board. We see in the last example above how the ISTs' collective considerations draw on the principle of treating students as sense-makers by orienting them to each other's strategies (lines 1-4). 
Fig. 7 Student strategies on a quick image represented on the board

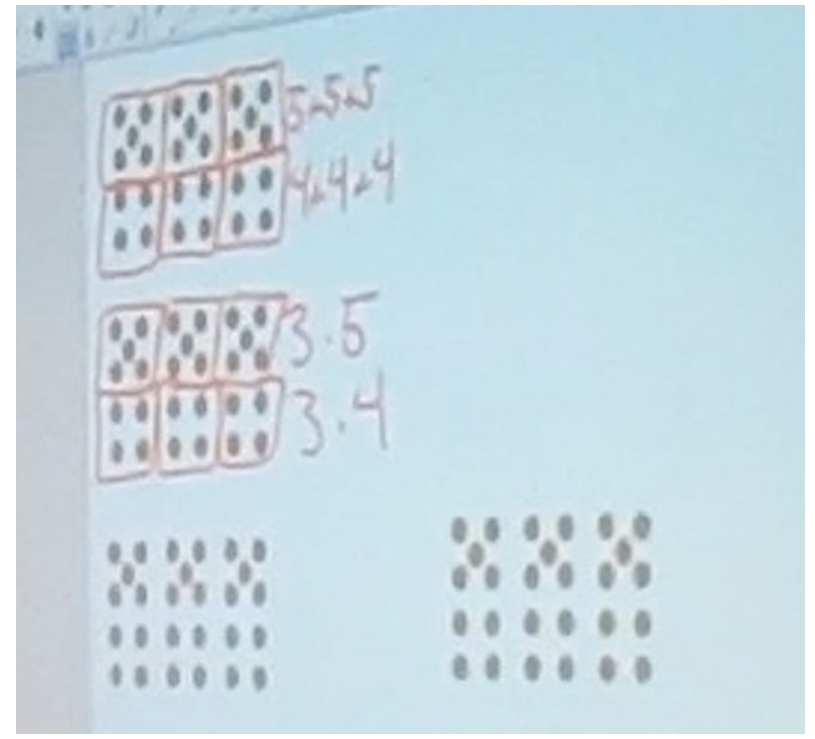

\section{Facilitating student talk}

Using talk moves (Chapin et al. 2009), such as revoicing, repeating, reasoning, wait time and turn and talk, which encourage students to engage in mathematical talk, was an important aspect of the MAM project. Two of these talk moves were particularly addressed in the TTOs, namely wait time and turn and talk. The participants initiated TTOs, suggesting that the teacher might ask students to turn and talk, and sometimes they argued why this was a good time to use this particular talk move. Below we give one example from a rehearsal using a quick image that illustrates this. The goal was that the students should learn about the distributive property of multiplication.

We join the rehearsal in group 2 after the teacher has presented two student strategies on the board (Fig. 7):

\footnotetext{
1 IST1 Should we ask the students to turn and talk before they offer their ideas?

2 Teacher Turn and talk to start with [right after the teacher has presented the task]

3 TE Yeah. What do you people think about that?

4 IST2 Then we're expanding the process

5 IST1 But then they'll all [the students] feel that they have talked about their way of thinking

6 IST2 Yeah, but I see this both ways. Because this will be quite a long sequence to get to where we want to go [the learning goal for the lesson]

7 IST1 It goes pretty quick to start with

8 Teacher They [the students] can talk a little bit before they start to tell me their ideas

9 IST1 But there's the risk that they [the students] might copy what someone else has said, and won't offer their own ideas. They might feel that the others have found a way that is quicker and [unclear]. Then we might not get that $5+5+5$ [the sentence at the top of the board]

10 Teacher Perhaps we get less variation now at the start

11 IST3 Perhaps you [teacher] should rather use turn and talk when you have some examples on the board, and ask if they [the students] see any connections
} 
12 Teacher We did say that we wanted to use turn and talk when we wanted to get them to work towards our goal [for the lesson], later in the lesson. (Session 3, November 24, 2016, quick image, group 2)

IST1 suggested that the teacher might ask the students to turn and talk before she presents their strategies on the board (line 1) and then argued why (line 5). IST2 politely disagreed (line 4), and a discussion on the pros and cons of using turn and talk ensued. One advantage they pointed to was that all the students could share their ideas with each other (line 5). Disadvantages they mentioned were that the process might be too long, and the students might copy ideas from each other so that their contributions might be less varied (lines 6, 9, 10). IST3 suggested that the teacher could use turn and talk when she wanted to look at connections between particular strategies (line 11). The teacher pointed out that they had agreed to do that when they co-planned the lesson (line 12).

The participants also often suggested that the teacher might give students time to think before they turn and talk to their classmates:

\begin{tabular}{lll}
\hline 1 & IST1 & $\begin{array}{c}\text { Should we ask them to turn and talk or } \\
\text { should we let them think individually } \\
\text { first? }\end{array}$ \\
3 & Teacher & Let them think individually first, I think \\
4 & IST2 & And then turn and talk \\
& IST1 & $\begin{array}{c}\text { Yes, that's what I think too. (Session 6, } \\
\text { May 4, 2017, strings, group 2) }\end{array}$
\end{tabular}

IST1 asked if the teacher should give the students time to think before they share their strategies (line 1). The teacher and other ISTs all agreed that this was a good idea (lines 2-4).

The two examples illustrate how TTOs enabled learning situations for the ISTs. The participants considered together how to use talk moves to facilitate student talk, particularly the turn and talk and wait time approaches. More specifically, the ISTs negotiated how and when to use a particular talk move and how to combine different talk moves.

The first example also illustrates how the TTOs created learning situations for the ISTs' collective sensemaking of connecting the enactments of practices to principles of ambitious teaching. The discussion is framed around two principles of ambitious teaching: providing equitable access to learning by providing space for students' contributions (lines 1 , 9,10 ) and treating students as sense-makers by giving them space to explain their thinking, orienting them to each other's thinking and giving them space to make sense of it (lines 1 , $5,8)$. Moreover, this example illustrates how the teacher educator encourages the ISTs to engage in the discussion (line 3 ) and the collective process of negotiating meaning.

\section{Discussion}

In this article, we have explored the patterns of use of TTOs in rehearsals, and we have considered how TTOs enable the ISTs to learn key practices and principles of ambitious teaching. As in the study of novice teachers conducted by Lampert et al. (2013), our findings show that there is a back-and-forth pattern between teaching and TTOs in rehearsals. Lampert et al. (2013) note that this directs the attention of the participants more towards particular principles and practices of ambitious teaching. Participants can 
try things multiple times, receive feedback and discuss particular aspects of practice. Our findings show that most of the TTOs were initiated by ISTs (76\%) and that half of the TTOs were initiated by the lead teacher, indicating that ISTs are active and engaged participants in the collective learning of ambitious teaching. The findings further indicate that the teacher educators and ISTs have established a community that welcomes questions, and where contributing with questions is an important part of the collective learning.

In their study of novice teachers, Lampert et al. (2013) found a markedly different distribution when it came to the initiation of TTOs. In their case, $78 \%$ of TTOs were initiated by the teacher educator. There may be various reasons for this difference. One reason may be that the ISTs had more classroom teaching experience, a better understanding of the context and were better able to identify aspects of the teaching situation that warrant discussion than the novice teachers were. Kazemi et al. (2016) point out that the nature of rehearsals is indeed affected by novice teachers' experiences with instructional activities and the classroom. Another explanation might be the role assumed by the teacher educators and the fact that they and ISTs are considered to be more like peers in the context of our study.

\section{Rehearsals as a valuable approximation of practice}

The rehearsals provided the ISTs with learning situations for collectively learning the practices of ambitious teaching and how to use them in a principled and adaptive manner in response to student contributions (Grossman et al. 2009). These opportunities for enactment and investigation have the potential to help ISTs to develop a shared understanding of the practices and principles of ambitious teaching, which can enable adaptive teaching. The ISTs tried out different practices, asked questions, gave each other feedback and offered specific suggestions on what the teacher could do in a particular situation, drawing on key principles of ambitious teaching. There was also room for short and longer discussions, the participants could consider different aspects of possible teacher strategies and moves, and they argued why or why not the teacher should choose a particular strategy or steer the instruction in a particular direction. The teacher educators and ISTs often used "we": "Should we...?", "What do we think?", "Could we say that...?", which highlights the sense of the collective. The ISTs opened up their instructional decision-making to one another and shared their thinking on how to use students' responses to promote all students' understanding of mathematics. The ISTs both initiated and were active participants in TTOs and thus positioned themselves as responsible and contributing members of the community (Greeno 2007).

Being responsive to student thinking and using their emergent ideas to reach the goal for the lesson is one of the most complex and challenging parts of ambitious teaching (Richards and Robertson 2015), and ISTs need to practise with colleagues to learn this (Kavanagh et al. 2020). Our study indicates that the rehearsals supported the ISTs in learning how to respond to students' in-the-moment ideas while teaching and to develop a shared conceptual framework or shared repertoire that can enable them to use the practices and principles adaptively in new situations. Kavanagh et al. (2020) explored rehearsals with ISTs, finding that by constraining what ISTs could approximate; for example, by reducing teachers' choices of task selection, it was possible to focus more tightly on how to understand and respond to students' contributions as they emerged. In our study, the common starting point of an instructional activity allowed for rich considerations of teacher decision-making in relation to particular student contributions. 
We found that rehearsals were a setting within which the ISTs developed, negotiated and shared their understanding of ambitious teaching (Wenger 1998). Knowledge was negotiated by the teacher educator and ISTs in collaboration as they engaged in making sense of and reshaping each other's ideas in the discussions. The analyses showed that the ISTs were making sense together through the questions they asked each other, the discussions that took place and how they engaged in discussions. We found that the TTOs focused predominantly on the following practices: use of representations; aiming towards goals; launching problems; facilitating student talk; and organising the board (see Table 2). As in a previous study on rehearsals with ISTs (Valenta and Wæge 2017), we found that the use of representations was one of the most frequently recurring topics. This is not surprising, given that instructional activities are designed to promote this particular practice (Lampert et al. 2010). Our findings revealed that the balance between representing students' ideas as accurately as possible and simultaneously considering the mathematical correctness of the representations, for example number sentences, was a recurrent theme in the TTOs. We also found that the TTOs enabled the ISTs to make sense together on how the teacher could represent students' ideas in a mathematically correct way without altering the flow of the students' thinking, for example by using arrows instead of equal signs.

According to Chapman (2016), more research is needed to understand how PD can engage teachers in all aspects of practice so they can "understand them as interconnected and not separate aspects of practice" (p. 2). Our study revealed that rehearsals enabled ISTs to work simultaneously on multiple practices in relation to each other. For our purposes here, we focused on TTOs in rehearsals only. However, we note that discussions in rehearsals naturally depend on and are shaped by interactions in the other phases of the learning cycle.

We have examined one element of the MAM project, namely rehearsals, identified the structure of rehearsals and provided insight into how they create learning situations for ISTs' collective learning of ambitious mathematics teaching. While this study provides insight into rehearsals in the context of $\mathrm{PD}$, more research is required. We need to provide systematic descriptions of each element of the cycles of enactment and investigation and understand how the different elements enable ISTs to collectively learn ambitious teaching practices. One limitation of our study is that it did not address how the rehearsals might affect the ISTs' subsequent teaching in their classrooms. It has also been beyond the scope of the study to investigate whether the focus of the TTOs differs with different initiators. Studying how the IST's learning within this project might lead to changes in their classroom practice will also be of importance for future research.

Acknowledgements Open Access funding provided by NTNU Norwegian University of Science and Technology (incl St. Olavs Hospital - Trondheim University Hospital). We would like to thank Elham Kazemi, Mona Nosrati and May Britt Postholm for their helpful comments on earlier drafts of this article.

Funding No external funding.

Code availability The codes are described in the manuscript.

\section{Compliance with ethical standards}

Conflict of interest No conflict of interest or competing interests.

Ethics approval The project is approved by the Norwegian Centre for Research Data. 
Informed consent A letter of information providing information about the project, including information about research publications, was given to all participants in the study. The letter of information is approved by the Norwegian Centre for Research Data. We have gained written informed consents from all participants in the study.

Availability of data and material The data of this study are not available due to their containing information that could compromise the privacy of research participants.

Open Access This article is licensed under a Creative Commons Attribution 4.0 International License, which permits use, sharing, adaptation, distribution and reproduction in any medium or format, as long as you give appropriate credit to the original author(s) and the source, provide a link to the Creative Commons licence, and indicate if changes were made. The images or other third party material in this article are included in the article's Creative Commons licence, unless indicated otherwise in a credit line to the material. If material is not included in the article's Creative Commons licence and your intended use is not permitted by statutory regulation or exceeds the permitted use, you will need to obtain permission directly from the copyright holder. To view a copy of this licence, visit http://creativecommons.org/licenses/by/4.0/.

\section{References}

Ball, D. L., \& Bass, H. (2003). Toward a practice-based theory of mathematical knowledge for teaching. In B. Davis, \& E. Simmt (Eds.), Proceedings of the 2002 annual meeting of the Canadian Mathematics Education Study Group (pp. 3-14). Edmonton, AB: CMESG/GCEDM.

Ball, D. L., \& Even, R. (2009). Strengthening practice in and research on the professional education and development of teachers of mathematics: Next steps. In R. Even \& D. L. Ball (Eds.), The professional education and development of teachers of mathematics: The 15th ICMI Study (pp. 255-260). New York: Springer.

Chapin, S. H., O'Connor, C., \& Anderson, N. C. (2009). Classroom discussions. Using math talk to help students learn. Sausalito: Math Solutions.

Chapman, O. (2016). Approaches and challenges in supporting mathematics teachers' change. Journal of Mathematics Teacher Education, 19(1), 1-5.

Corbin, J., \& Strauss, A. (2008). Qualitative research. Los Angeles: Sage Publications.

Desimone, L. M. (2009). Improving impact studies of teachers' professional development: Toward better conceptualizations and measures. Educational Researcher, 38(3), 181-199.

Fauskanger, J., \& Bjuland, R. (2019). Learning ambitious teaching of multiplicative properties through a cycle of enactment and investigation. Mathematics Teacher Education and Development Journal, 21(1), 125-144.

Garet, M. S., Porter, A. C., Desimone, L., Birman, B. F., \& Yoon, K. S. (2001). What makes professional development effective? Results from a national sample of teachers. American Educational Research Journal, 38(4), 915-945.

Ghousseini, H. (2017). Rehearsals of teaching and opportunities to learn mathematical knowledge for teaching. Cognition and Instruction, 35(3), 188-211.

Ghousseini, H., Beasley, H., \& Lord, S. (2015). Investigating the potential of guided practice with an enactment tool for supporting adaptive performance. Journal of the Learning Sciences, 24(3), 461-497.

Gibbons, L. K., Kazemi, E., Hintz, A., \& Hartmann, E. (2017). Teacher time out: Educators learning together in and through practice. NCSM Journal of Mathematics Education Leadership, 18(2), 28-46.

Goldsmith, L. T., Doerr, H. M., \& Lewis, C. C. (2014). Mathematics teachers' learning: a conceptual framework and synthesis of research. Journal of Mathematics Teacher Education, 17(1), 5-36.

Greeno, J. G. (2007). Toward the development of intellective character. In E. W. Gordon \& B. L. Bridglall (Eds.), Affirmative development (pp. 17-48). Lanham, MD: Rowman \& Littlefield.

Grossman, P., Hammerness, K., \& McDonald, M. (2009). Redefining teaching, re-imagining teacher education. Teachers and Teaching: Theory and Practice, 15(2), 273-289.

Grossman, P., Kavanagh, S. S., \& Dean, C. G. P. (2018). The turn towards practice in teacher education. In P. Grossman (Ed.), Teaching core practices in teacher education (pp. 1-14). Cambridge, MA: Harvard Education Press.

Grossman, P., \& McDonald, M. (2008). Back to the future: Directions for research in teaching and teacher education. American Educational Research Journal, 45(1), 184-205. 
Jacobs, V. R., Franke, M. L., Carpenter, T. P., Levi, L., \& Battey, D. (2007). Professional development focused on children's algebraic reasoning in elementary school. Journal for Research in Mathematics Education, 38(3), 258-288.

Kavanagh, S. S., Metz, M., Hauser, M., Fogo, B., Taylor, M. W., \& Carlson, J. (2020). Practicing responsiveness: Using approximations of teaching to develop teachers' responsiveness to students' ideas. Journal of Teacher Education, 71(1), 94-107.

Kazemi, E. (2017). Teaching a mathematics methods course: Understanding learning from a situative perspective. In S. Kastberg, A. Tyminski, A. Lischka, \& W. Sanchez (Eds.), Building support for scholarly practices in mathematics methods (pp. 49-65). Charlotte, NC: Information Age.

Kazemi, E., Ghousseini, H., Cunard, A., \& Turrou, A. C. (2016). Getting inside rehearsals: Insights from teacher educators to support work on complex practice. Journal of Teacher Education, 67(1), 18-31.

Kazemi, E., \& Hubbard, A. (2008). New directions for the design and study of professional development: Attending to the coevolution of teachers' participation across contexts. Journal of Teacher Education, $59(5), 428-441$.

Kazemi, E., \& Wæge, K. (2015). Learning to teach within practice-based methods courses. Mathematics Teacher Education and Development Journal, 17(2), 125-145.

Kennedy, M. (2016). How does professional development improve teaching? Review of Educational Research, 86(4), 945-980.

Lampert, M., Beasley, H., Ghousseini, H., Kazemi, E., \& Franke, M. L. (2010). Using designed instructional activities to enable novices to manage ambitious mathematics teaching. In M. K. Stein \& L. Kucan (Eds.), Instructional explanations in the disciplines (pp. 129-141). New York, NY: Springer.

Lampert, M., Franke, M. L., Kazemi, E., Ghousseini, H., Turrou, A. C., Beasley, H., et al. (2013). Keeping it complex: Using rehearsals to support novice teacher learning of ambitious teaching. Journal of Teacher Education, 64(3), 226-243.

Lampert, M., Ghousseini, H., \& Beasley, H. (2015). Positioning novice teachers as agents in learning teaching. In L. Resnick, C. Asterhan, \& S. Clarke (Eds.), Socializing intelligence through academic talk and dialogue (pp. 363-374). Washington, DC: American Educational Research Association.

Lave, J. (1991). Situating learning in communities of practice. In L. Resnick, J. Levine, \& S. Teasley (Eds.), Perspectives on socially shared cognition (pp. 63-82). Washington, DC: APA.

McDonald, M., Kazemi, E., \& Kavanagh, S. S. (2013). Core practices and pedagogies of teacher education: A call for a common language and collective activity. Journal of Teacher Education, 64(5), 378-386.

Putnam, R. T., \& Borko, H. (2000). What do new views of knowledge and thinking have to say about research on teacher learning? Educational Researcher, 29(1), 4-15.

Richards, J., \& Robertson, A. D. (2015). A review of the research on responsive teaching in science and mathematics. In A. D. Robertson, R. E. Sherr, \& D. Hammer (Eds.), Responsive teaching in science and mathematics (pp. 36-55). London: Routledge.

Valenta, A., \& Wæge, K. (2017). Rehearsals in work with in-service mathematics teachers. In T. Dooley, \& G. Gueudet (Eds.), Proceeding of the tenth congress of the European society for research in mathematics education, CERME10 (pp. 3881-3888). Dublin, Ireland: Institute of Education, Dublin City University and ERME.

van Es, E. A., \& Sherin, M. G. (2008). Mathematics teachers "learning to notice" in the context of a video club. Teaching and Teacher Education, 24(2), 244-276.

Vangrieken, K., Meredith, C., Packer, T., \& Kyndt, E. (2017). Teacher communities as a context for professional development: A systematic review. Teaching and Teacher Education, 61, 47-59.

Wenger, E. (1998). Communities of practice: Learning, meaning, and identity. Cambridge: Cambridge University Press.

Publisher's Note Springer Nature remains neutral with regard to jurisdictional claims in published maps and institutional affiliations. 